\title{
WALTER BENJAMIN E AS CIDADES: CHOQUE, VIVÊNCIA E MEMÓRIA
}

\author{
Leonardo Barci Castriota ${ }^{1}$
}

\begin{abstract}
Resumo: A realidade contemporânea parece marcada pela "estetização", que perpassaria todas as esferas do vivido, chegando a própria realidade, no limite, a ser percebida como um "construto estético". Ao procurar explicar esse fenômeno, o filósofo alemão Wolfgang Welsch argumenta que essa hiperestetização da realidade corresponderia a uma necessidade insaciável de se ter cada vez mais "vivências" (Erlebnisse), estando o mundo sendo crescentemente transformado num "espaço de vivências" (Erlebnisraum). Ao tomar esse caminho explicativo, Welsch nos remete a uma discussão tradicional no pensamento alemão, muito bem representada pela abordagem de Walter Benjamin (1893-1940), que relaciona a temática da vivência às mudanças trazidas pela modernidade aos domínios da percepção, da recepção da arte e da própria memória.
\end{abstract}

Palavras-Chave: Cidade, Vivência, Choque, Memória, Arte.

\begin{abstract}
The contemporary reality seems to be marked by the "aesthetics" that runs through all spheres of life, in a way that the reality itself is ultimately be perceived as a kind of "aesthetic construct." In seeking to explain this phenomenon, the German philosopher Wolfgang Welsch argues that hiperaestheticization of reality corresponds to an insatiable need to have more and more "experiences" (Erlebnisse), which leads the world increasingly into a "space of experience" (Erlebnisraum). By taking this explanatory path, Welsch takes a traditional discussion on German thought, well represented by the approach of Walter Benjamin (1893-1940), which relates the themes of experience to the changes brought by modernity to the fields of perception, the reception of art and memory itself.
\end{abstract}

Keywords: City, Experience, Shock, Memory, Art.

Muito se discute hoje sobre a chamada "estetização" da realidade contemporânea ${ }^{2}$. Há pouco mais de uma década, o filósofo alemão Wolf-

1 MACPS/Universidade Federal de Minas Gerais (UFMG); arquiteto e urbanista, doutor em Filosofia e professor titular da Escola de Arquitetura da UFMG; pesquisador do CNPq, foi pesquisador visitante da Rockfeller Foundation e do Getty Conservation Institute; foi Diretor de Patrimônio de Belo Horizonte, Presidente do IAB-MG e Diretor da Escola de Arquitetura da UFMG. Autor de diversos livros, entre os quais se destacam Arquitetura $e$ documentação (Annablume, 2011) e Patrimônio cultural: conceitos, políticas e instrumentos (Annablume, 2009). Endereço eletrônico: leonardo.castriota@pq.cnpq.br.

2

Ao mesmo tempo em que se aponta para uma crescente homogeneização nas cidades contemporâneas, modificadas pelo pós-fordismo, costuma-se destacar também que esse 
gang Welsch, em seu importante trabalho Grenzgänge der Ästhetik, já apontava para esse processo de "estetização" da realidade, que, a seu ver, perpassaria todas as esferas do vivido, chegando a própria realidade, no limite, a ser percebida como um "construto estético". Se esse "boom estetizante" atingia cada vez mais elementos, indo da "estilização" individual até a economia e a teoria, ele se mostraria com muita força, no próprio espaço urbano, que seria como um primeiro nível desse processo, podendo se ver pelo mundo todo áreas urbanas inteiras sendo reestruturadas esteticamente, para se tornarem "elegantes", "chiques" e "centros de animação".

Na sua descrição irônica, as cidades estariam sofrendo uma espécie de facelifting, intervenção cirúrgica estética, que atingiria igualmente os centros históricos, as antigas áreas industriais ou degradadas das cidades e mesmo as novas periferias que se formavam, não escapando desse boom estetizante nem as pedras do calçamento das ruas, nem as maçanetas das portas. "Se pudessem", conclui, "as sociedades industriais ocidentais avançadas transformariam in toto o meio-ambiente urbano, industrial e natural num cenário hiperestético" (WELSCH, 1996, p. 10).

Ao aprofundar sua análise desse fenômeno onipresente, Wolfgang Welsch nos apresenta uma chave importante de compreensão da cena contemporânea: para ele, essa hiperestetização da realidade corresponderia, no fundo, a uma necessidade insaciável de se ter cada vez mais "vivências" (Erlebnisse), estando o mundo sendo crescentemente transformado num "espaço de vivências" (Erlebnisraum). Para o filósofo, a "vivência" seria, então, a palavra-chave nesse processo de "embelezamento" do mundo.

Toda butique e todo café têm que ser hoje "ativadores de vivências". As estações de trem na Alemanha já não são chamadas "estações de trem" mas se denominam, desde que passaram a ser adornadas pela arte, "mundo de vivências com conexões ferroviárias". Em nosso dia a dia, saímos de um "escritório de vivências" para uma "vivência de compras", descansamos numa "vivência gastronômica" e desembarcamos, por fim, em casa numa "vivência do habitar". Há inclusive sugestões de se encenar os monumentos

outro fenômeno correlato a essa homogeneização: nessas cidades a estética - que por muito tempo parecera relegada frente à funcionalidade - passa a ocupar um papel proeminente, articulando um discurso visual poderoso e global. De fato, um "boom estetizante" parece perpassar hoje os diversos níveis da vida cotidiana, do styling individual e dos produtos de design à transformação massiva dos espaços públicos, com amplo rebatimento nas cidades.

48 Número temático: Desenho e Educação: Cultura Visual e Cidade. A Cor das Letras - UEFS, $n$. 
- por exemplo, aqueles sobre o terror nazista - como "espaços de vivência" ${ }^{3}$.

Se em sua análise recorre a autores contemporâneos como Gerhardt Schultz, que, nos anos 1990, falava de uma "sociedade de vivências" (Erlebnisgesellschaft) como chave para uma "sociologia do presente" ${ }^{4}$, Welsch nos remete, na verdade, a uma temática, já consolidada há bastante tempo na tradição alemã, que contrapõe a "experiência" (Erfahrung) à "vivência" (Erlebnis). Dentre os diversos autores que se situam em tal tradição, a abordagem de Walter Benjamin (1893-1940) nos parece muito adequada para enfocar a hiperestetização da realidade contemporânea, na medida em que esse filósofo judeu-alemão relaciona a temática da vivência às mudanças trazidas pela modernidade aos domínios da percepção, da recepção da arte e da própria memória.

De fato, no esquema delineado por Benjamin, a "experiência (Erfahrung)", que permitia um conhecimento e uma moral concretos e não reduzidos no mundo pré-moderno e que era transmitida predominantemente pela narração, vai ser substituída, na modernidade, pela "vivência (Erlebnis)" individual e solitária do indivíduo moderno. "Erlebnis", define Leandro Konder, vai ser, em contrapartida à experiência sempre coletiva, "a vivência do indivíduo privado, isolado, é a impressão forte, que precisa ser assimilada às pressas, que produz efeitos imediatos" (KONDER, 1988, p. $72)^{5}$ Este artigo vai acompanhar, então, as formulações decisivas de Walter Benjamin, procurando situar a relação que ele estabelece entre a vivência da grande metrópole, o choque e a memória do homem moderno.

WELSCH, 1996, p. 11.

4 SCHULTZ, 2001.

5 No Passagen-Werk Benjamin afirma: "A experiência (Erfahrung) é o produto do trabalho e a vivência (Erlebnis), a fantasmagoria do ocioso" (GS, V, 1, p. 540). Ainda sobre esta distinção, Martin Jay anota: "Numa distinção hoje muito celebrada, Benjamin dividiu a experiência em Erfahrung - a integração de eventos na memória das tradições coletivas e pessoais - e Erlebnis - o isolamento de eventos com relação a qualquer desses contextos significativos, comunitários ou individuais. Exemplificada pela erosão da capacidade do contador de histórias no sentido de criar uma história coerente, em função da substituição da narrativa pelas informações desconexas de nossa diária, a Erfahrung (experiência prática) foi amplamente suplantada pela incoerência desprovida de sentido da Erlebnis (experiência emotiva) no mundo culturalmente empobrecido do capitalismo avançado" (JAY, 1988, p. 69). 


\section{O CHOQUE E A VIVÊNCIA MODERNA}

Esta é a forma, portanto, com a qual Benjamin, nesse ensaio sobre Baudelaire, introduz a importante noção de "choque (Schock)", que aqui vai determinar, a seu ver, toda a estrutura da "vivência" do homem moderno. Com efeito, para o filósofo, a modernidade se caracterizaria pela intensificação levada, ao paroxismo, das situações de choque, em todos os domínios. O choque se impõe como realidade onipresente, manifestando-se nos diversos aspectos da vida, da experiência de "tomar um banho de multidão", proposta por Baudelaire, até o trabalho mecânico repetitivo do operário. Nelson Brissac Peixoto, em seu livro A Sedução da Barbárie explicita:

A recepção de "chocs" tornou-se regra geral da experiência moderna. O indivíduo aí é como uma marionete. O ritmo do movimento na rua ou da circulação monetária, a técnica, o consumo e logo a arte moderna submeteriam a sensibilidade do homem moderno a um adestramento completo. $\mathrm{Na}$ multidão, na fábrica ou numa mesa de jogo, todos estão submetidos à sorte, ao acaso. Até suas fisionomias e gestos estão deformados, parecem ridículos: "procedem do repertório do palhaço". [...] Trabalhador e jogador vivem como autômatos, cujas ações são impermeáveis à experiência, desprovidas de qualquer memória. Como o indivíduo na multidão. Cada movimento da máquina, como cada lance no jogo, é hermeticamente separado dos que o precederam, igualmente carente de todo conteúdo. O choque do operário que lida com máquinas corresponde ao do transeunte na multidão: passar por acontecimentos excluídos do seu contexto de experiência ${ }^{6}$.

A experiência do choque terminaria por produzir um novo tipo de sensibilidade, onde "a instância psíquica encarregada de captar e observar o choque passa a predominar sobre as instâncias encarregadas de armazenar as impressões na memória", como explica Rouanet. ${ }^{7}$ Diferentemente da sensibilidade tradicional, onde consciente e inconsciente, esforço voluntário e eventos involuntários se combinavam numa memória que ainda podia evocar o passado e as experiências coletivas, o homem moderno vê-se reduzido a uma percepção concentrada na interceptação do choque, em sua neutralização. Brissac comenta: "A tomada de consciência nesse caso tem a função de, como em Simmel, servir de proteção contra os estímulos, subli-

PEIXOTO, 1983, p. 144.

7

ROUANET, 1981, p. 47-48.

50 Número temático: Desenho e Educação: Cultura Visual e Cidade. A Cor das Letras - UEFS, $n$. 
mar os impactos, amadurecendo o susto em angústia ou diversão, para não sucumbir ao espanto" ${ }^{8}$.

Se o choque vai ser uma realidade onipresente, o filósofo parece indicar que, no plano de uma teoria da experiência, determinadas vivências traumáticas não seriam passíveis de serem absorvidas, "incorporadas", pela experiência no seu sentido amplo. É o que podemos depreender de uma passagem como a que consta tanto em "Experiência e Pobreza", de 1933, quanto de "O Narrador", de 1936, onde Benjamin observa não ser estranho que no final da $1^{\text {a }}$ Guerra Mundial, os combatentes tenham voltado do campo de batalha "não mais ricos, e sim mais pobres em experiência comunicável":

Porque nunca houve experiência mais radicalmente desmoralizada que a experiência estratégica pela guerra de trincheiras, a experiência econômica pela inflação, a experiência do corpo pela guerra de material e a experiência ética pelos governantes. Uma geração que ainda fora à escola num bonde puxado por cavalos se encontrou ao ar livre numa paisagem em que nada permanecera inalterado, exceto as nuvens, e debaixo delas, num campo de forças de torrentes e explosões, o frágil e minúsculo corpo humano (OE 1, p. 198).

Seguindo o modelo freudiano do "trauma", Benjamin sugere mesmo ser desastroso o contato não-mediato entre o sujeito e a realidade material, um potencial assalto destrutivo contra seu inconsciente despreparado, similar ao assalto na origem das neuroses traumáticas. ${ }^{9}$ Esta seria a chave através da qual Benjamin interpreta a lírica de Baudelaire como uma tentativa de se produzir uma poesia fundamentada em "uma experiência para a qual o choque se tornou a norma". Como reação ao choque, uma poesia dessa natureza teria que ter, necessariamente, "um alto grau de conscientização", evocando "a ideia de um plano atuante em sua composição" (OE 3, p. 110). Daí porque, como poeta, Baudelaire ter se especializado em "aparar os choques, de onde quer que proviessem, com o seu ser espiritual e físico", usando, por exemplo, a imagem da esgrima para representar esse

8 PEIXOTO, 1983, p. 145. É importante observar aqui que o filósofo, como em Rua de Mão Única, também vai apresentar a experiência na vida contemporânea como uma forma degradada da Erfahrung plena que reinava num mundo não-alienado, pré-capitalista. A esse respeito, confira COHEN, 1995, p. 206.

9 A esse respeito, confira COHEN, 1995, p. 207. 
processo, imagem que aproxima o trabalho do poeta à experiência do homem na multidão ${ }^{10}$.

Esta proximidade aponta-nos para a aproximação - central para a teoria da experiência benjaminiana - entre "a imagem do choque e o contato com as massas urbanas" (OE 3, p. 113): para o filósofo vai ser a vivência da cidade moderna, notadamente a imersão na massa amorfa de passantes, que conforma as estruturas da experiência do homem contemporâneo. Não há aqui qualquer abordagem moral, ou mesmo ideológica do fenômeno da multidão: "Não se pode pensar em nenhuma classe, em nenhuma forma de coletivo estruturado. Não se trata de outra coisa senão de uma multidão amorfa de passantes, de simples pessoas nas ruas", explica (OE 3, p. 113).

Nada mais distante das descrições de um Engels, que, como Marx, entendia que tinha como missão "extrair daquela massa amorfa, na época bajulada por um socialismo literário, a massa férrea do proletariado" (OE 3, p. 114) ${ }^{11}$. Para o poeta francês, contrariamente, não haveria como visar o fenômeno da multidão de forma externa: "a massa lhe é tão pouco exterior", formula Benjamin, "que nos permite seguir de perto, em sua obra, o modo como ele resiste ao seu envolvimento e à sua atração" (OE 3, p. 115). A experiência da multidão seria, assim, tão intrínseca a Baudelaire, que "em vão buscamos nele a sua descrição": diferentemente de um Victor Hugo, o poeta "não descreve nem a população, nem a cidade". Na visão do poeta, a imagem de uma se fundiria, de forma caracteristicamente moderna, com a

10 Em seu ensaio, Benjamin refere-se aos versos do poema O Sol de As Flores do Mal: "Ao longo dos subúrbios, onde nos pardieiros / Persianas acobertam beijos sorrateiros, / Quando o impiedoso sol arroja seus punhais / Sobre a cidade e o campo, os tetos e os trigais, / Exercerei a sós a minha estranha esgrima, / Buscando em cada canto os acasos da rima / Tropeçando em palavras como nas calçadas, / Topando imagens desde há muito já sonhadas." (Charles Baudelaire, As flores do Mal; trad. Ivan Junqueira, Rio de Janeiro, Nova Fronteira, 1985, 2. ed., p. 319 apud BENJAMIN, Walter, OE 3, p. 112). Em Parque Central, Benjamin anota: "O choque como princípio poético de Baudelaire: a estranha esgrima da cidade dos Quadros Parisienses já não é pátria. É palco e país estrangeiro" (OE 3, p. 164).

11 Benjamin chama a atenção para como, ao lado de uma reação moral de repulsa, a multidão termina provocando uma "reação estética" em Engels: "a velocidade com que os transeuntes passam precipitados o afeta de forma desagradável." O filósofo não vai deixar de lembrar a origem de Engels, que provinha de uma "Alemanha ainda provinciana", da mesma forma que Hegel, que também manifestara reação semelhante em relação a Paris. (OE 3, p. 115).

52 Número temático: Desenho e Educação: Cultura Visual e Cidade. A Cor das Letras - UEFS, $n$. 
da outra: "sua multidão é sempre a da cidade grande; a sua Paris é invariavelmente superpovoada". Assim, por exemplo, se em "A uma Passante" nenhuma palavra é reservada à descrição da multidão, o desenvolvimento do poema repousaria inteiramente nela, "do mesmo modo como o curso do veleiro depende do vento" (OE 3, p. 116) ${ }^{12}$. A sua experiência - moderna - seria, de forma integral, determinada por ela:

Se sucumbia à violência com que ela o atraía para si, convertendo-o, enquanto flâneur, em um dos seus, mesmo assim não o abandonava a sensação de sua natureza inumana. Ele se faz seu cúmplice para, quase no mesmo instante, isolar-se dela. Mistura-se a ela intimamente para, inopinadamente, arremessá-la no vazio com um olhar de desprezo (OE 3, p. 121).

A vivência do choque do homem na metrópole liga-se também a uma temporalidade diferente da temporalidade da experiência, que, como vimos, articulava a narração. Se nessa o tecer lento da narrativa, em seu ritmo orgânico, permite que se depositem as camadas da experiência - contribuindo também decisivamente para a memorização, para a integração do narrado na experiência do ouvinte - , naquela vai predominar o ritmo mecânico, febril da multiplicidade de choques na multidão. Usando uma imagem baudelaireana, Benjamin utiliza-se da figura do jogador, para apresentar a vivência moderna do tempo ${ }^{13}$ : um tempo infernal, de repetição e

12 Numa caracterização literária do fenômeno da multidão, que se impunha à experiência do homem moderno no período, Benjamin lança mão também do conto de Poe, $\mathrm{O} \mathrm{Ho}$ mem da Multidão, que revelaria "alguns traços notáveis, e basta apenas segui-los para encontrar instâncias sociais tão poderosas, tão ocultas, que poderiam ser incluídas entre as únicas capazes de exercer, por vários meios, uma influência tão profunda quanto sutil sobre a criação artística" (OE 1, p. 119). O filósofo vai contrapor também, numa espécie de "fenomenologia da multidão" que propõe, o "homem da multidão", "em cujas pegadas o narrador do conto de Poe percorre a Londres noturna em todos os sentidos", com o tipo do "flâneur", que, na lírica baudelaireana, vaga por Paris. Em comparação à capital inglesa, a Paris de Baudelaire guardaria ainda "alguns traços dos velhos bons tempos": "Ainda havia balsas cruzando o Sena onde mais tarde deveria se lançar os arcos das pontes. No ano da morte de Baudelaire, um empresário ainda podia ter a ideia de fazer circular quinhentas liteiras para comodidade de habitantes abastados. Ainda se apreciavam as galerias onde o flâneur se subtraía da vista dos veículos, que não admitem o pedestre como concorrente" (OE 3, p. 121-122). (Em outras palavras, a Paris de Baudelaire ainda conservaria alguns traços pré-modernos).

Flávio René Kothe chama a atenção para como, na leitura benjamiana, o jogador corresponderia, na obra de Baudelaire, ao trabalhador moderno: "Como a sua visão sócio- 
reiteração do sempre-igual. Articulando esta analogia, o filósofo parte da observação de que o "empenho em vencer e ganhar dinheiro" do jogador deveria ser atribuído muito mais à "avidez, de uma determinação obscura", do que propriamente a um "desejo", "que pertence à categoria da experiência" (OE 3, p. 128-129). Explicitando tal colocação, o filósofo formula:

Quando se projeta um desejo distante no tempo tanto mais se pode esperar por sua realização. Contudo o que nos leva longe no tempo é a experiência que o preenche e o estrutura. Por isso o desejo realizado é o coroamento da experiência (OE 3, p. 129).

Num mundo atravessado pelas correspondências - como é o mundo da experiência - as dimensões do espaço e do tempo se relacionariam, como vimos, podendo a "distância no espaço" assumir o lugar da "distância no tempo": "esta a razão porque a estrela cadente, precipitando-se na infinita distância do espaço, se transformou no símbolo do desejo realizado". No jogo, por outro lado, "a bolinha de marfim rolando para a próxima casa numerada, a próxima carta em cima de todas as outras" seria "a verdadeira antítese da estrela cadente" (OE 3, p. 129). Não haveria nenhum resquício de experiência no tempo do jogador, aquele "tempo infernal, em que transcorre as existências daqueles a quem nunca é permitido concluir o que foi começado": o "recomeçar sempre" seria a ideia regulativa do jogo, como também "a do trabalho assalariado", acrescenta o filósofo ${ }^{14}$. Com essa última analogia, Benjamin utiliza-se de um dos procedimentos de análise que aplica com frequência à obra de Baudelaire: mostrar como numa imagem manifesta de sua lírica, subjazeria, muitas vezes, uma imagem latente. Sob a imagem do jogador - aquele que está condenado a sempre recomeçar, num tempo refratário a qualquer experiência -, esconde-se a figura do operário, também ele "um homem espoliado em sua experiência - um homem moderno" (OE 3, p. 130). Para Benjamin, por mais que o poeta francês desconhecesse a realidade do operariado contemporâneo, ele estaria "fascinado por um processo, em que o mecanismo reflexo e acionado no operário pela máquina pode ser examinado mais de perto no indivíduo ocioso, como em um espelho", os "jogos de azar" (OE 3, p. 126-127).

política era limitada, Baudelaire não chega a retratar o trabalhador, mas mostra várias vezes o jogador" (KOTHE, 1978, p. 103).

14 "Recorda: o Tempo é sempre um jogador atento / Que ganha, sem furtar, cada jogada! É a lei.", cita Benjamin (Charles Baudelaire, As flores do Mal; trad. Ivan Junqueira, Rio de Janeiro, Nova Fronteira, 1985, 2. ed., p. 313, citado em OE 3, p. 130).

54 Número temático: Desenho e Educação: Cultura Visual e Cidade. A Cor das Letras - UEFS, $n$. 
As analogias entre os dois processos seriam múltiplas, a seu ver: num e noutro não faltaria "a inutilidade, o vazio, o não poder concluir".

Seu (= do trabalhador assalariado, LBC) gesto, acionado pelo processo de trabalho automatizado, aparece também no jogo, que não dispensa o movimento rápido da mão fazendo a aposta ou recebendo a carta. 0 arranque está para a máquina, como o lance para o jogo de azar. Cada operação com a máquina não tem qualquer relação com a precedente, exatamente porque constitui a sua repetição rigorosa. Estando cada operação com a máquina isolada da precedente, da mesma forma que um lance na partida do jogo de seu precedente imediato, a jornada do operário assalariado representa, a seu modo, um correspondente à féria do jogador. Ambas as ocupações estão igualmente isentas de conteúdo (OE 3, p. 127, grifos nossos).

$E$, tanto quanto a experiência em seu sentido amplo apresenta uma relação profunda com a atividade artesanal - com a sua temporalidade, ritmo e respeito pela matéria a plasmar - , também a vivência do homem moderno relaciona-se intimamente com a sua maneira de produzir. Neste aspecto, cabe destacar que, enquanto no artesanato a conexão entre as etapas do trabalho vai ser "contínua", nas atividades do "operário de fábrica na linha de montagem", esta conexão vai se apresentar como "autônoma" e "coisificada". "A peça entra no raio de ação do operário, independentemente de sua vontade. E escapa dele da mesma forma arbitrária.", formula Benjamin (OE 3, p. 125). Diferentemente, portanto, da repetição pressuposta no artesanato (e na narração), onde, em cada peça, o artífice podia deixar o seu "vestígio (Spur)", diferenciando-a, na produção mecanizada e automatizada, a marca humana desaparece: trata-se agora de uma "repetição rigorosa", infernal ${ }^{15}$. "Uniformidade", tal a nova palavra de ordem:

Uniformidade de indumentária, do comportamento, e, não menos importante, a uniformidade dos gestos. O sorriso - exemplo a dar o que pensar. É

15 Neste aspecto, Anthony Giddens, em "A vida em uma sociedade pós-tradicional”, apoiando-se em Freud, também descreve a modernidade como "compulsiva", referindo-se a uma "inclinação emocional para a repetição", "em grande parte inconsciente ou pouco compreendida", que seria de natureza completamente diferente da repetição pressuposta na tradição: "O passado continua vivo, mas, em vez de ser reconstruído de modo ativo de acordo com a tradição, tende a dominar a ação de um modo quase semicausal. A compulsividade, quando socialmente generalizada, é, na verdade, tradição sem tradicionalismo: repetição que se põe no caminho da autonomia, em vez de estimulá-la" (GIDDENS, 1997, p. 89). 
presumivelmente, o que está subentendido no hoje familiar keep smiling, que atua como um amortecedor gestual (OE 3, p. 125) ${ }^{16}$.

Baseando-se no Marx de $O$ Capital, Benjamin mostra que o próprio processo de formação difere entre os dois tipos de trabalho: enquanto o operário se forma pelo "adestramento" - mecânico - , o artífice só poderia ser formado pela "prática". Com base nesta, segundo Marx, "qualquer setor da produção" encontraria "através da experiência (Erfahrung) uma forma técnica que lhe corresponda; e lentamente, este setor a aperfeiço$a^{\prime 17}$ (grifos de Walter Benjamin). É interessante perceber a ênfase que o autor dá aqui aos termos "experiência" e "lentamente" - lembrando-nos do processo lento, acumulativo e de sedimentação pressuposto no trabalho artesanal -, numa contraposição clara à produção moderna. Esta, por sua vez, ao se articular através da "especialização inteiramente limitada a uma única tarefa", erigiria à categoria de virtude "a falta de qualquer formação", que termina gerando o "operário não-especializado", "o mais profundamente degradado pelo condicionamento imposto pela máquina". Para esse, de fato, "a prática não serve para nada", tornado-se seu trabalho "alheio a qualquer experiência" (Seine Arbeit ist gegen Erfahrung abgedichtet) (OE 3, p. 126; GS I, 2, p. 623) ${ }^{18}$. Neste sentido, Andrew Benjamin chama a atenção para as consequências trazidas, para o âmbito de experiência, pelo tipo de "repetição rigorosa" a que está submetido o operário, completamente diferente daquela repetição de que tratara em "O Narrador":

16 Aqui não há como não lembrar da passagem onde Jean Baudrillard descreve o "sorriso grau zero" que encontra na América: "O sorriso que cada um nos dirige ao passar, crispação simpática dos maxilares sob o efeito do calor humano. É o eterno sorriso da comunicação, aquele pelo qual a criança se desperta para a presença de outros, ou pelo qual se interroga desesperadamente sobre a presença de outros, o equivalente do grito primevo do homem só no mundo. Seja como for, aqui sorriem para você, e não é por cortesia nem por sedução. Esse sorriso significa apenas a necessidade de sorrir. É um pouco como o gato de Chester: flutua ainda nos rostos muito tempo depois que todo o afeto desapareceu" (BAUDRILLARD, 1986, p. 30).

17 MARX, Karl. Das Kapital. Kritik der politischen Ökonomie. Ungekürzte Ausgabe nach der 2. Aufl. Von 1872, Ed. Karl Korsch, tomo 1, Berlim, 1932, p. 459 apud BENJAMIN, Walter. OE 3, p. 125.

18 Este tipo de reação pode ser flagrada também na "fenomenologia da multidão", que já apontamos, onde os transeuntes desenhados por Poe "se comportam como se, adaptados à automatização, só conseguissem se expressar de forma automática". Seu comportamento vai ser, então, uma "reação a choques" (OE 3, p. 126).

56 Número temático: Desenho e Educação: Cultura Visual e Cidade. A Cor das Letras - UEFS, n. 
Naquela instância a importância da repetição estava em que ela envolvia um repetir que retinha e transmitia. A repetição se tornava aquilo através do qual a tradição era continuada. O mesmo não era nunca o mesmo porque ele era suplementado pela sua própria repetição. [...] O trabalhador na máquina não repete retendo. A repetição quebra a continuidade porque 0 ato de repetir - o "recontar" - é em cada instante o mesmo e, portanto, novo ${ }^{19}$.

A ação repetitiva do operário seria típica do homem moderno, privado simultaneamente de experiência e memória. É a "experiência de quem perdeu a experiência", nas palavras de Rouanet, a experiência daquele "que está preso nas malhas de um universo cíclico, e que em vez de ser regido pela história, é regido pelo destino" ${ }^{20}$. (Assim, não é de se estranhar que, nesse contexto, Benjamin aponte seguidamente para a reemergência do mito, em toda sua potência, na modernidade).

Como anotamos, para o filósofo, haveria uma espécie de "rivalidade histórica" entre as "diversas formas da comunicação", que se sucederiam uma à outra num aprofundamento crescente da "pobreza" moderna. Nesta linha de raciocínio, num mundo marcado profundamente pela experiência do choque, até mesmo o penoso esforço de reconstrução de uma totalidade exercido pelo romance também vai se tornando anacrônico, "arcaico", e vai sendo substituído por outra "forma", ainda com menor capacidade de "integração". "Na substituição da antiga forma narrativa pela informação, e da informação pela sensação reflete-se a crescente atrofia da experiência" (OE 3, p. 107), formula o filósofo.

De fato, segundo Benjamin, com a consolidação da burguesia - "da qual a imprensa, no alto capitalismo, é um dos instrumentos mais importantes" - teria se destacado uma forma de comunicação que, "por mais antigas que fossem suas origens, nunca havia influenciado decisivamente a forma épica": a informação. "Agora ela exerce essa influência.", constata. "Ela é tão estranha à narrativa como o romance, mas é mais ameaçadora e, de resto, provoca uma crise no próprio romance" (OE 1, p. 202). A informação nem derivaria da experiência, nem se endereçaria à experiência do leitor, sendo nisso "incompatível com o espírito da narrativa". Se a arte da

19 BENJAMIN, 1989, p. 130.

20 ROUANET, 1981, p. 110. Rouanet em Édipo e o Anjo chama a atenção para a proximidade dessas considerações benjaminianas ao tratamentoque Freud reservaria à "compulsão de repetição", descrevendo pessoas cujas vidas dariam a impressão de "um destino que as peersegue, de uma orientação demoníaca de sua existência". Aqui ele reencontra o "tempo do infeerno" benjaminiano, espécie de eterno retorno individual, a que estaria condenado o homem moderno sem memória. 
narração seria rara hoje, a difusão da informação vai ser, sem dúvida, "decisivamente responsável por esse declínio" (OE 1, p. 203).

Aqui voltamos à ligação entre experiência e memória: os jornais vão constituir, para o filósofo, "um dos muitos indícios" de que "se reduziram as chances dos fatos exteriores se integrarem à nossa experiência", passando "as inquietações de nossa vida interior" a ter um "caráter irremediavelmente privado", sendo fruto do acaso "se cada indivíduo adquire ou não uma imagem de si mesmo, e se pode ou não se apossar de sua própria experiência" (OE 3, p. 106). Não é propósito da imprensa fazer com que o leitor incorpore as informações que lhe fornece: pelo contrário, sua ação visa "isolar os acontecimentos do âmbito onde pudessem afetar a experiência do leitor", enuncia. E mesmo que assim o quisesse, não o conseguiria, já por suas próprias características - novidade, concisão, inteligibilidade, falta de inter-relação entre as notícias, paginação e estilo linguístico. "Karl Kraus não se cansou de demonstrar a que ponto o estilo jornalístico tolhe a imaginação dos leitores" (OE 3, p. 107) ${ }^{21}$, anota Benjamin. Com isso, a informação não pode se integrar de modo algum à tradição, já que, por sua própria natureza, nem se incorpora à esfera de experiência do leitor, nem pode ser por ele transmitida como um traditum.

O fato é que a informação articularia uma dialética entre o distante - espacial e temporal - e o próximo, diametralmente oposta àquela que marcava a narração. Nesta última, vai haver sempre, como anotamos, um movimento de "atualização" do distante: algo longínquo - no espaço ou no tempo - aparece, através do narrador, como próximo, podendo se incorporar à experiência do ouvinte. Isto só vai se tornar possível, no entanto, porque "o Saber, que vinha de longe - do longe espacial das terras estranhas, ou longe temporal contido na tradição - , dispunha de uma autoridade que era válida mesmo que não fosse controlável pela experiência", explica Benjamin (OE 1, p. 202-203). Assim, o "exótico" e o "arcaico" podiam, sem mais, ser incorporados, sem que tivessem que vir acompanhados de explicações ou submetidos a um escrutínio redutor ${ }^{22}$.

21 É interessante conferir como Benjamin subscreve as críticas que Karl Kraus dedica à imprensa, cabendo chamar a atenção para o papel puramente instrumental que a linguagem vai ter nesta forma de comunicação: o jornalismo seria a expressão acabada da "função transformada da linguagem no mundo do capitalismo tardio" (GS II, 1, p. 335).

Para Benjamin, metade da arte narrativa estaria "em evitar explicações". Nisto Leskov, como bom narrador, seria "magistral": "O extraordinário e o miraculoso são narrados com a maior exatidão, mas o contexto psicológico da ação não é imposto ao leitor. Ele é 58 Número temático: Desenho e Educação: Cultura Visual e Cidade. A Cor das Letras - UEFS, n. 
Com a informação, dar-se-ia o contrário: ela "aspira a uma verificação imediata", precisando ser, antes de mais nada, "compreensível 'em si e para si'"; o que não significa, na verdade, que a informação contenha mais "verdade" que a narrativa: muitas vezes mesmo ela "não é mais exata que os relatos antigos", escreve Benjamin, que acrescenta: "Porém, enquanto esses relatos recorriam frequentemente ao miraculoso, é indispensável que a informação seja plausível" (OE 1, p. 203). A informação seria, assim, em todos aspectos, oposta à narração, pressupondo, como anota José GuiIherme Merquior, a "dissolução do conteúdo harmônico do fluxo das vivências individuais" ${ }^{23}$. Assim Benjamin poder afirmar: "Cada manhã recebemos notícias de todo o mundo. E, no entanto, somos pobres em histórias surpreendentes" (OE 1, p. 203) ${ }^{24}$.

\section{REFERÊNCIAS}

ADORNO, Theodor W.; HORKHEIMER, Max. Dialética do esclarecimento: fragmentos filosóficos. Rio de Janeiro: J. Zahar, 1985.

BENJAMIN, Walter. Magia e técnica, arte e política. Trad. Sérgio Paulo Rouanet. São Paulo:Brasiliense, 1985. Obras Escolhidas, v. 1.

livre para interpretar a história como quiser, e com isso, o episódio narrado atinge uma amplitude que não existe na informação" (OE 1, p. 203). Esta "abertura" potencial da narrativa, permitiria a sua permanência: "Ela se assemelha a essas sementes de trigo que durante milhares de anos ficaram fechadas hermeticamente nas câmaras das pirâmides e que conservam até hoje suas forças germinativas" (OE 1, p. 204).

"Mas a informação não afeta menos o valor 'artesanal' da narrativa e seu 'pendant', que é o contato virtual entre o acontecimento narrado e a experiência individual do ouvinte. O ideal do estilo jornalístico: a brevidade e a 'objetividade' com que as notícias são dadas, sem correlação umas com as outras, na página do jornal - tende a isolar a informação da experiência pessoal, tanto da do narrador (cujo estilo se torna perfeitamente anônimo) quanto da do leitor. Cada indivíduo passa a ler, sozinho, a notícia que não o envolve, assim como não envolveu quem a relata" (MERQUIOR, 1969, p. 125). Richard Wollin comenta, a esse respeito: "Assim, nós sabemos mais sobre tudo, no entanto esse conhecimento é mais pobre em qualidade: cessou de estar relacionado àquelas questões assim chamadas últimas que estão diretamente relacionadas com o sentido da vida. $O$ aumento na quantidade permanece para sempre incapaz de compensar a diminuição na qualidade" (WOLLIN, 1989, p. 221).

24 O filósofo complementa: “A razão é que os fatos já nos chegam acompanhados de explicações. Em outras palavras: quase nada do que acontece está a serviço da narrativa, e quase tudo está a serviço da informação. Metade da arte narrativa está em evitar explicações." (OE 1, p. 203). 
BENJAMIN, Walter. Charles Baudelaire: um lírico no auge do capitalismo. Trad. José Carlos Martins Barbosa e Hemerson Alves Baptista. São Paulo: Brasiliense, 1989. Obras Escolhidas, v. 3.

CASTRIOTA, Leonardo Barci. Patrimônio cultural. conceitos, políticas, instrumentos. São Paulo: Annablume, 2009.

COHEN, Margaret. Profane Illumination. Walter Benjamin and the Paris of Surrealist Revolution. Berkeley: University of California Press, 1995.

DELGADO, Manuel. Ciudades postizas. El 'centro histórico' como falsificación. $G+C$. Revistainternacional de gestión y cultura contemporánea. Granada: Área de Trabjo, 2009. N..2. La ciudad temática, p. 18-21.

GAGNEBIN, Jeanne-Marie. Lukács e a crítica da cultura. In: ANTUNES, Ricardo; RÊGO, Walquiria Domingues Leão. (Org.). Lukács: um Galilleu no século XX. São Paulo: Boitempo, 1996.

JAY, Martin. As ideias de Adorno. Trad. Adail Ubirajara Sobral. São Paulo: Cultrix: Ed. USP, 1988.

KONDER, Leandro. Walter Benjamin: o marxismo da melancolia. Rio de Janeiro: Campus, 1988.

MUÑOZ, Francesc. Urbanalización. Paisajes comunes, lugares globales. Barcelona: Gustavo Gilli, 2008.

PEIXOTO, Nelson Brissac. A sedução da barbárie: o marxismo da modernidade. São Paulo: Brasiliense, 1983.

SCHULTZ, Gerhardt. Die Erlebnisgesellschaft: Kultursoziologie der Gegenwart. Frankfurt am Main: Campus, 1992.

SPERLING, D. M. Event: architecture and art in the era of mediatized experience. In: $X$ Congresso da Sociedade Iberomamericana de Gráfica Digital (SIGraDi), 2006, Santiago. X SIGraDi - Sociedade Iberoamericana de Gráfica Digital, 2006.

UNITED NATIONS CENTRE FOR HUMAN SETTLEMENTS (HABITAT). Cities in a Globalizing World: Global Report on Human Settlements 2001. London: Earthscan Publications, 2001.

WELSCH, Wolfgang. Grenzgänge der Ästhetik. Stuttgart: Reclam, 1996. 